\title{
SEMENTES DE MORINGA OLEIFERA NA CLARIFICAÇÃO DE EFLUENTE DE INDÚSTRIA DE INGREDIENTES PARA ALIMENTAÇÃO ANIMAL: COMPARAÇÃO COM O COAGULANTE CONVENCIONAL E ESTUDO DAS CONDIÇÕES OPERACIONAIS
}

\author{
Luciane Pozzobon ${ }^{1}$ \\ Aniela Pinto Kempka ${ }^{2}$
}

\begin{abstract}
Resumo: A semente de Moringa oleifera caracteriza-se por possuir capacidade coagulante e floculante, sendo, portanto, utilizada na clarificação de água principalmente por comunidades de baixa renda no interior do Brasil, onde é cultivada para esta aplicação. Devido a esta capacidade de clarificação, vários estudos apontam o potencial uso desta semente na etapa primária do tratamento de efluentes industriais constituídos de matéria orgânica. Neste sentido, este estudo objetivou comparar o uso de Moringa oleifera e de sulfato de ferro (coagulante convencional) na clarificação do efluente de indústria de ingredientes para alimentação animal. Ainda, utilizando a técnica de planejamento experimental, buscou-se as melhores condições operacionais em termos de agitação e concentração de coagulante. Para a maioria dos experimentos, os percentuais de clarificação obtidos com o uso de sementes de Moringa e de sulfato de ferro não diferiram estatisticamente. As condições operacionais que apresentaram os melhores percentuais de clarificação com uso de Moringa foram a concentração de $138 \mathrm{mg} / \mathrm{L}$ de semente triturada e $100 \mathrm{rpm}$ de agitação, chegando-se a 53,20\% de clarificação, seguida da condição de 200 $\mathrm{mg} / \mathrm{L}$ de semente e $50 \mathrm{rpm}$, com 48,40\%. Avaliando-se um possível incremento no percentual de clarificação, fez-se uma decantação prévia do efluente antes da adição da semente de Moringa, onde verificou-se que a adição direta da semente no efluente não decantado previamente apresentou os melhores resultados para clarificação e quanto a remoção de DQO, não havendo, portanto, a necessidade de uma decantador primário para retirada do excesso de sólidos, como convencionalmente é utilizado.
\end{abstract}

Palavras-chave: Efluente, Moringa oleifera, clarificação, parâmetros de processo.

Abstract: The seed of Moringa oleifera is characterized by having capacity coagulant and flocculant capacity, and is therefore used in water clarification mainly by low-income communities in the interior of Brazil, where it is cultivated for this application. Due to this ability to clarify, several studies point to the potential use of this seed in the primary stage of industrial wastewater treatment consisting of organic matter. In this sense, this study aimed to compare the use of Moringa oleifera and the iron sulphate (conventional coagulant) in the effluent clarification of feed ingredients industry. Still, using the technique of experimental design was sought to optimize the operating conditions in terms of agitation and concentration of coagulant. For most experiments, the percentage of clarification obtained from the use of seeds of Moringa and the iron sulphate did not differ statistically. Operational conditions showed the best percentage clarification using Moringa were the concentration of $138 \mathrm{mg} / \mathrm{L}$ of seed and $100 \mathrm{rpm}$ agitation, coming to $53.20 \%$ for clarification, then the condition of $200 \mathrm{mg} / \mathrm{L}$ seed and $50 \mathrm{rpm}(48.40 \%)$. Evaluating a possible increase in the percentage of clarification, there was a prior decanting effluent before addition of Moringa seed, where it was found that the direct addition of the seed in

\footnotetext{
${ }^{1}$ Departamento de Engenharia de Alimentos - Centro de Educação Superior do Oeste - Universidade do Estado de Santa Catarina. E-mail: luhpzb@ hotmail.com

${ }^{2}$ Departamento de Engenharia de Alimentos - Centro de Educação Superior do Oeste - Universidade do Estado de Santa Catarina. E-mail: aniela.kempka@udesc.br
} 
the effluent decanted previously not had the best results, and showed no hence the need for a primary sedimentation tank to remove excess solids such as is conventionally used.

Keywords: Effluent, Moringa oleifera, clarification, process parameters.

\section{INTRODUÇÃO}

A atividade da indústria de alimentos não deveria ser tão prejudicial ao meio ambiente devido a seus despejos serem de origem orgânica, mas pelo grande volume gerado $\mathrm{e}$ às altas concentrações de nutrientes, sólidos em suspensão e gorduras, se estes não forem tratados adequadamente antes de seu lançamento nos corpos d'água, poderão causar grave dano ambiental (Schmitt et al., 2010).

Empresas que possuem em seu efluente uma alta carga orgânica utilizam a flotação com a adição de polímero para redução primária da carga orgânica. Este material coagula e flocula a matéria orgânica solúvel e/ou emulsificada, reduzindo seus teores de forma a enquadrar 0 efluente dentro das especificações do projeto (Lenhari e Hussar, 2010).

Indústrias de ingredientes para alimentação animal utilizam matériasprimas caracterizadas como resíduos de frigoríficos de bovinos, suínos e aves. Como características principais dos efluentes de frigoríficos, podem-se citar as altas concentrações de óleos de graxas e Demanda Bioquímica de Oxigênio (DBO). Estima-se que a concentração de matéria orgânica nos efluentes, incluindose o sangue e fezes, pode chegar a DQO de $12.000 \mathrm{mgO}_{2} / \mathrm{L}$. Se o efluente for decantado pode-se reduzir a carga orgânica para até $3.000 \quad \mathrm{mgO}_{2} / \mathrm{L}$ (Pacheco, 2006; Arvanitoyannis e Ladas, 2008).

A coagulação é um processo comum utilizado para a remoção de matéria orgânica em suspensão em águas, sendo utilizados vários agentes químicos como sais de alumínio e ferro, coagulantes mais utilizados (Ghebremichael et al., 2005; Pritchard et al., 2010 b, Sánchez-Martin et al., 2012).

Um dos problemas associados ao uso do sulfato de alumínio, por exemplo, é a geração de um elevado volume de lodo contendo o cátion $\mathrm{Al}^{3+}$, o que dificulta a disposição final deste material no meio ambiente (Monaco et al., 2010). Ainda entre as desvantagens do uso de sulfato de alumínio ou de ferro tem-se o elevado custo de aquisição e os efeitos nocivos à saúde humana (Yin, 2010).

Historicamente, coagulantes de origem vegetal tem sido utilizados para tratamento de água antes do advento dos sais químicos (Ndabigengesere et al., 1995). Extratos vegetais naturais, como Moringa oleifera, Jatropha curcas, goma guar, Strychnos potatorum, Hibiscus sabdariffa e Clidemia angustifolia foram usados para purificação de água por muitos séculos. Em particular, $M$. oleifera é classificada como uma das melhores plantas para purificação de água (Pritchard et al., 2010a), tendo ainda como vantagens ser biodegradável, de baixo custo e gerar volumes menores de lodo (Formentini-Schmitt et al., 2014).

Os agentes coagulantes naturais têm demonstrado vantagens em comparação aos químicos no tratamento de águas e efluentes em relação à biodegradabilidade, baixa toxicidade e baixo índice de produção de lodos residuais (Moraes, 2004, Yin, 2010). Mas, mesmo com o uso de um coagulante natural, o lodo pode possuir uma alta concentração de metais pesados em sua composição, porém, estes possivelmente são oriundos da agua bruta utilizada no tratamento (Silva et al., 2012).

As sementes de Moringa oleifera podem ser utilizadas em substituição aos sais metálicos cloreto férrico, sulfato de alumínio e PCA (cloreto de polialumínio) usualmente empregados pela indústria (Silva e Matos, 2008). Neste sentido estudos apontaram que em comparação com o alumínio, as sementes de Moringa oleifera não alteraram significativamente o pH e a alcalinidade da água, não causando assim, problemas de corrosão (Gallão et al., 2006). 
A Moringa oleifera Lam pertence à família Moringaceae, nativa da Índia. Foi introduzida no Brasil por volta de 1950 sendo encontrada na região Nordeste, principalmente nos Estados do Maranhão, Piauí e Ceará (Ndabigengesere et al., 1995).

Consiste em uma árvore de crescimento rápido e altamente adaptável, além de ter baixo custo de produção e rendimento elevado de sementes, sendo que para a clarificação da água as espécies que apresentam bons resultados são principalmente a Moringa oleifera Lam e Moringa stenopetola (Mendes e Coelho, 2007; Vieira et al., 2012).

O favorecimento na clarificação de águas é justificado pela presença de aminoácidos com forte capacidade de aglutinação (ácido glutâmico, prolina, metionina, e arginina) que atuam como floculantes, aglutinando e sedimentando partículas sólidas presentes na água, o que possibilita eliminar a turbidez, micropartículas, fungos, bactérias e vírus. Os agentes ativos são proteínas catiônicas com massa molecular entre 12 e $14 \mathrm{KDa}$, com ponto isoelétrico entre 10 e 11, cujo principal mecanismo de coagulação consiste em adsorção e neutralização de carga (Ndabigengesere et al., 1995).

Vários trabalhos já demostraram a eficiência da Moringa oleifera no tratamento de efluentes agroindustriais. Formentini-Schmitt et al. (2014) ao estudarem a eficiência do composto ativo de Moringa oleifera extraída com soluções salinas na tratabilidade de águas residuárias da indústria de laticínios obtiveram remoções $98,3 \%$ na cor aparente, $97,1 \%$ na turbidez e $58,9 \%$ na DQO.

Portanto, o objetivo deste trabalho foi comparar o uso de sementes de Moringa oleifera e sulfato de ferro na clarificação do efluente de indústria de ingredientes para alimentação animal bem como otimizar as condições operacionais em termos de agitação e concentração de coagulante.

\section{METODOLOGIA}

O efluente, oriundo do processamento de ossos, vísceras e sangue, foi coletado na entrada da Estação de Tratamento de Efluentes (ETE) de uma indústria de ingredientes para alimentação animal localizada na região oeste de Santa Catarina. As sementes de Moringa oleifera foram fornecidas pela Fundação Desumar Queiroz (Fortaleza-CE).

\subsection{Estudo comparativo da clarificação do efluente utilizando a sementes de Moringa oleifera e o coagulante convencional}

A primeira etapa do estudo teve como objetivo comparar o uso de sementes de Moringa oleifera e um coagulante convencional (sulfato de ferro) na clarificação do efluente. Para tanto, utilizou-se um Delineamento Composto Central Rotacional (DCCR) com pontos axiais, mostrado na Tabela 1 , visando verificar a influência da agitação (rpm) e da concentração dos coagulantes (mg/L) no percentual de clarificação.

Tabela 1 - Delineamento Composto Central Rotacional (DCCR) com pontos axiais utilizado na clarificação do efluente de indústria de ingredientes para alimentação animal utilizando Moringa oleifera e sulfato de ferro como coagulantes.

\begin{tabular}{lcc}
\hline $\begin{array}{c}\text { Experi- } \\
\text { mento }\end{array}$ & $\begin{array}{c}\text { Agitação } \\
(\mathbf{r p m})\end{array}$ & $\begin{array}{c}\text { Concentração de } \\
\text { coagulante } \\
(\mathbf{m g} / \mathbf{L})\end{array}$ \\
\hline E1 & $50(-1)$ & $200(-1)$ \\
E2 & $50(-1)$ & $500(+1)$ \\
E3 & $150(+1)$ & $200(-1)$ \\
E4 & $150(+1)$ & $500(+1)$ \\
E5 & $30(-1,41)$ & $350(0)$ \\
E6 & $170(+1,41)$ & $350(0)$ \\
E7 & $100(0)$ & $138(-1,41)$ \\
E8 & $100(0)$ & $561(+1,41)$ \\
E9 $(C)$ & $100(0)$ & $350(0)$ \\
E10 $($ C) & $100(0)$ & $350(0)$ \\
\hline C $=$ ponto central do planejamento experimental
\end{tabular}

As faixas de concentração de Moringa oleifera e sulfato de ferro, o 
tempo de agitação e intervalos de velocidade de agitação foram fixados tendo como base os estudos Paterniani et al. (2009), Lima et al. (2010) e Schmitt et al. (2010). Todos os experimentos foram realizados com a utilização em separado da semente e do coagulante convencional e em duplicatas.

\subsection{Clarificação do efluente adicionando 0 coagulante diretamente no efluente bruto em comparação com a clarificação do efluente previamente decantado e posteriormente coagulado}

$\mathrm{Na}$ segunda etapa do estudo, procedeu-se a decantação prévia do efluente durante 30 minutos, tempo este obtido em testes prévios, sendo posteriormente determinado o percentual de clarificação. A este efluente préclarificado foi adicionada a semente de Moringa oleifera, sendo realizados os experimentos do planejamento cujos níveis e valores das variáveis estão na Tabela 1. A clarificação total foi definida como a soma do percentual da préclarificação do efluente e a clarificação obtida utilizando-se a Moringa oleifera.

\subsection{Preparo dos experimentos de clarificação}

As sementes de Moringa oleifera foram trituradas em um liquidificador industrial (Metalúrgica Siemsen) para obtenção de partículas de 18 a 20 mesh. Para todos os experimentos, os coagulantes foram adicionados em Erlenmeyers de $250 \mathrm{~mL}$ na concentração de acordo com o DCCR. Posteriormente, foram adicionados $100 \mathrm{~mL}$ do efluente bruto e os Erlenmeyers acondicionados em agitador orbital (Solab SL 222), sendo mantidos em agitação durante 30 minutos a temperatura de $25^{\circ} \mathrm{C}$. Após o tempo de agitação, o efluente foi transferido para uma proveta graduada de $100 \mathrm{~mL}$, sendo deixado em repouso para decantação durante 6 horas.

\subsection{Determinação do percentual de clarificação}

Para a obtenção dos valores de clarificação do efluente foi utilizada a metodologia de Paula et al. (2009) adaptada. As amostras foram analisadas em espectrofotômetro (Biospectro SP220), sendo obtidos os valores de transmitância a $670 \mathrm{~nm}$.

\subsection{Caracterização físico- química do efluente bruto e das amostras clarificadas}

Para a caracterização físico-química do efluente bruto e das amostras clarificadas procedeu-se as análises de Demanda Química de Oxigênio (DQO), alcalinidade total, sólidos totais e sólidos dissolvidos de acordo com o Standard Methods for the Examination of Water and Wastewater (APHA, 1998). Para a obtenção do $\mathrm{pH}$ utilizou-se um pHmetro com compensação de temperatura (Ion PHB - 500).

\subsection{Análise Estatística}

A análise estatística dos resultados experimentais foi realizada utilizando o software Statistica ${ }^{\circledR} 10.0$ (Statsoft, Inc.). Foi realizado o Teste de Tukey sendo também avaliados os efeitos isolados e de interação entre as variáveis do planejamento proposto com nível de 95 $\%$ de confiabilidade.

\section{RESULTADOS E DISCUSSÃO}

\subsection{Estudo comparativo da clarificação do efluente utilizando semente de Moringa oleifera e sulfato de ferro}

Na Tabela 2 estão os resultados da clarificação (\%) do efluente utilizando Moringa oleifera e sulfato de ferro como coagulantes para todos os experimentos do DCCR. Verifica-se que, para quase todos os experimentos (exceto E8), os valores do percentual de clarificação foram iguais ou superiores para o sulfato 
de ferro, porém, indiferente do coagulante utilizado, os percentuais de clarificação ficaram na faixa de 40 a $60 \%$.

Tabela 2- Resultados da clarificação (\%) do efluente utilizando Moringa oleifera e sulfato de ferro como coagulantes para todos os experimentos do DCCR.

\begin{tabular}{lcc}
\hline \multirow{2}{*}{$\begin{array}{c}\text { Experi- } \\
\text { mento }\end{array}$} & \multicolumn{2}{c}{ Clarificação (\%) } \\
\cline { 2 - 3 } & $\begin{array}{c}\text { Moringa } \\
\text { oleifera }\end{array}$ & $\begin{array}{c}\text { Sulfato de } \\
\text { ferro }\end{array}$ \\
\hline E1 & $48,40 \pm 5,09$ & $53,40 \pm 1,41$ \\
E2 & $44,40 \pm 3,39$ & $53,60 \pm 3,39$ \\
E3 & $43,40 \pm 0,28$ & $48,00 \pm 2,83$ \\
E4 & $45,40 \pm 0,28$ & $54,80 \pm 4,53$ \\
E5 & $44,80 \pm 2,83$ & $53,00 \pm 1,98$ \\
E6 & $39,40 \pm 0,28$ & $44,40 \pm 3,39$ \\
E7 & $53,20 \pm 2,26$ & $49,40 \pm 9,90$ \\
E8 & $46,00 \pm 2,26$ & $59,80 \pm 2,55$ \\
E9 (C) & 51,00 & 51,00 \\
E10 (C) & 50,40 & 56,00 \\
\hline C = ponto central do planejamento experimental.
\end{tabular}

Para verificar a influência das variáveis para cada um dos coagulantes em relação à clarificação (\%), efetuou-se a análise estatística dos resultados. Os Diagramas de Pareto obtidos, correspondentes aos processos com uso de Moringa oleifera e sulfato de ferro, estão mostrados na Figura 1.

Em relação aos efeitos das variáveis isoladas, para o processo utilizando Moringa oleifera (Figura 1a), tanto a concentração (C) como a agitação (A) apresentaram efeito significativo negativo, o que significa que a passagem do nível -1 para +1 do planejamento experimental leva a menores valores de percentuais de clarificação. Para o processo de clarificação utilizando sulfato de ferro (Figura 1b), apenas a concentração de coagulante apresentou efeito significativo positivo, o que significa que a passagem do nível -1 para +1 do planejamento experimental leva a uma maior clarificação (\%), ou seja, o aumento da concentração de coagulante contribui para o aumento do percentual de clarificação.

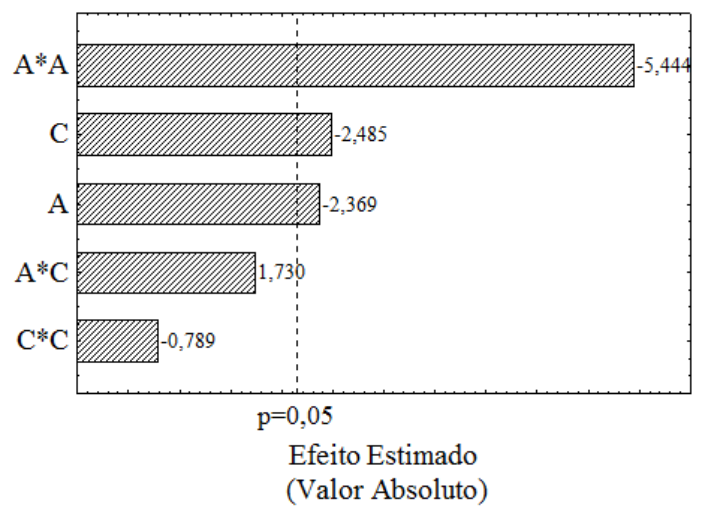

(a)

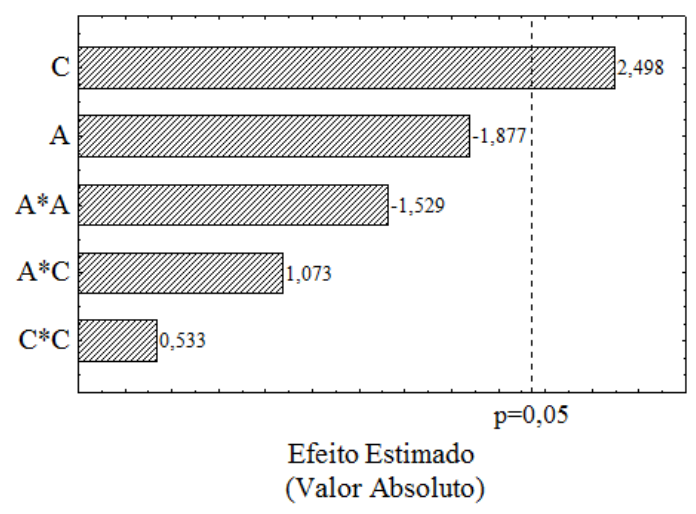

(b)

Figura 1- Diagramas de Pareto obtidos a partir da análise estatística dos resultados de clarificação (\%) utilizando (a)

Moringa oleifera (b) sulfato de ferro.

Através dos valores dos coeficientes de regressão, determinados com nível de $95 \%$ de significância, obteve-se os modelos matemáticos que representam a clarificação (\%), apresentados nas Equações 1 e 2 para o processo utilizando Moringa oleifera $\left(\mathrm{R}^{2}=0,87\right)$ e sulfato de ferro $\left(\mathrm{R}^{2}=0,89\right)$, respectivamente.

$$
\begin{array}{r}
\text { Clarificação }(\%)=42,770-0,010 . C \\
-0,259 . A-0,002 A^{2} \\
\text { Clarificação }(\%)=54,2012+0,028 . C
\end{array}
$$

Os modelos matemáticos apresentados nas Equações 1 e 2 permitiram a construção das Superfícies de Resposta correspondentes aos processos de clarificação, mostradas na Figura 2. 


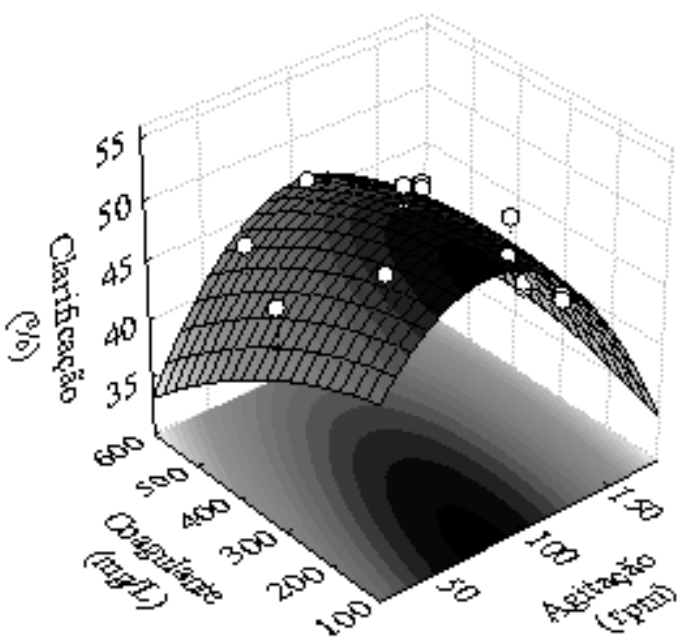

(a)

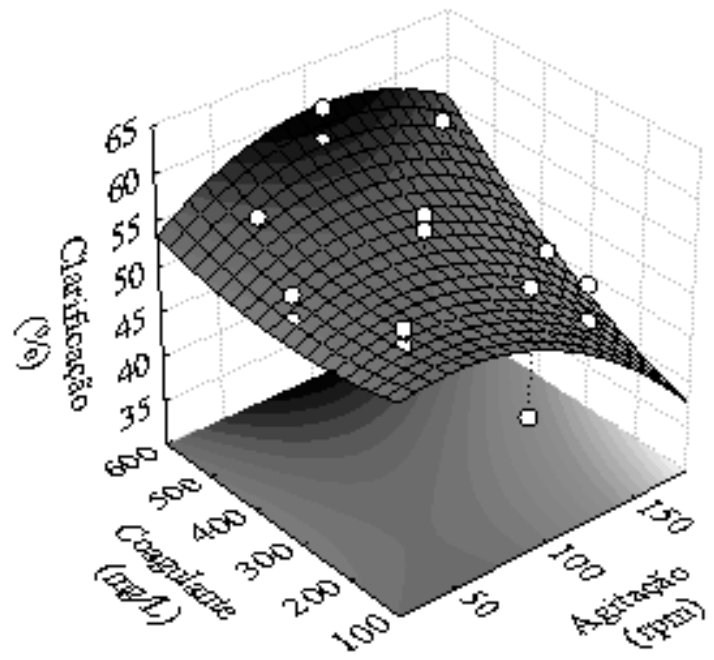

(b)

Figura 2 - Superfícies de Resposta obtidas para os processos de clarificação do efluente de indústria de ingredientes para alimentação animal utilizando (a) Moringa oleifera e (b) sulfato de ferro.

Observa-se que a região de maximização da clarificação (região em preto) difere para os processos, sendo que com o uso de Moringa oleifera (Figura 2a), encontra-se na região central dos valores de agitação entre 50 e $100 \mathrm{rpm}$ e de concentração de coagulante abaixo de $350 \mathrm{mg} / \mathrm{L}$, sendo os melhores resultados E7 (138 mg/L e agitação de $100 \mathrm{rpm})$, seguido de E1 (200 mg/L de semente e 50 rpm de agitação). Para o processo com o uso de sulfato de ferro (Figura 2b), observa-se que a região de maximização da clarificação fica em uma faixa mais ampla de agitação, porém em concentrações acima de $500 \mathrm{mg} / \mathrm{L}$ de coagulante.
Katayon et al. (2005) utilizaram semente de Moringa para a remoção de turbidez de água e verificaram que a dosagem ótima da semente foi de 400 $\mathrm{mg} / \mathrm{L}$ para água de alta turbidez com remoção de $90-98 \%$, e $160 \mathrm{mg} / \mathrm{L}$ para água de média turbidez, com remoção de 60-90\%, concentrações superiores a verificada no presente estudo (E7).

Pritchard et al. (2010b) utilizaram agitação de $200 \mathrm{rpm}$ por 30 segundos, seguida de $20 \mathrm{rpm}$ por 15 minutos e obtiveram $50 \%$ e $90 \%$ de redução de turbidez em águas turvas preparadas, utilizando concentrações de Moringa de 30 e $55 \mathrm{mg} / \mathrm{L}$ respectivamente.

O aumento da concentração de sulfato de ferro diretamente ligado ao aumento da clarificação torna-se uma desvantagem frente ao comportamento do processo de clarificação com uso de Moringa oleifera. Além das concentrações da Moringa oleifera ser inferiores, pode-se considerar o fato de que se caracteriza como um coagulante natural, cujo lodo resultante do processo poderia ser tratado e utilizado como fertilizante, sem haver excesso de um determinado contaminante no solo, como ocorreria com os íons de ferro. Portanto, diante do resultado, optou-se para a próxima etapa da pesquisa utilizar apenas a Moringa oleifera nos ensaios de clarificação.

Como vantagem adicional do uso da Moringa é que vários produtos úteis podem ser extraídos a partir da semente, como os óleos comestíveis, antes do coagulante ser fracionado. Sólidos residuais podem ser utilizados como alimento para animais e fertilizante, enquanto a casca da semente pode ser ativada e utilizada como adsorvente (Ghebremichael et al., 2005)

\subsection{Clarificação do efluente bruto adicionado de coagulante em comparação a clarificação do efluente previamente decantado $e$ posteriormente coagulado}

Para verificação de um possível incremento na clarificação do efluente, realizou-se os experimentos E1 e E7 (condições otimizadas) com efluente pré- 
decantado (sem adição de coagulante) simulando o decantador primário do sistema de tratamento de efluentes. $\mathrm{O}$ percentual de clarificação prévia do efluente da indústria de ingredientes para alimentação animal foi de $22,40 \%$.

A Tabela 3 mostra os resultados das médias do percentual de clarificação do efluente bruto com adição direta da semente de Moringa oleifera (valores estes obtidos dos ensaios para comparação com o sulfato de ferro) e os resultados das médias com a decantação prévia. Para os últimos, somou-se o percentual de clarificação obtido na decantação prévia com o resultado da clarificação obtido após a adição da semente para E1 e E7.

Tabela 3 - Médias do percentual de clarificação do efluente bruto com adição direta da semente de Moringa oleifera e médias do percentual de clarificação do efluente com a decantação prévia para E1 e E7.

\begin{tabular}{ccc}
\hline $\begin{array}{c}\text { Experi- } \\
\text { mento }\end{array}$ & $\begin{array}{c}\text { Clarificação (\%) } \\
\text { decantação } \\
\text { prévia }\end{array}$ & $\begin{array}{c}\text { Com } \\
\text { decantação } \\
\text { prévia }\end{array}$ \\
\hline E1 & $48,40^{\mathrm{A}} \pm 5,09$ & $33,02^{\mathrm{B}} \pm 1,10$ \\
E7 & $53,20^{\mathrm{A}} \pm 2,26$ & $26,52^{\mathrm{B}} \pm 0,11$ \\
\hline
\end{tabular}

Médias do percentual de clarificação seguidas de letras maiúsculas diferentes, na horizontal, diferem em nível de $95 \%$ de confiança $(\mathrm{p}<0,05)$ pelo Teste de Tukey.

Comparando-se os valores dos percentuais de clarificação para os experimentos sem decantação prévia e com decantação prévia, verifica-se que ocorre diferença significativa $(\mathrm{p}<0,05)$ entre os valores de clarificação e que estes valores, quando realizada a decantação prévia, foram inferiores aos valores de clarificação quando não realizada esta decantação.

Para E7, o valor de clarificação (\%) foi $50 \%$ maior quando adicionada a semente de Moringa oleifera triturada ao efluente bruto, em comparação com a clarificação obtida para o efluente prédecantado. Este comportamento pode ser justificado pela relação direta entre o aumento de turbidez da água (sólidos) e o aumento da atividade coagulante das sementes de Moringa (Okuda, 2001).
Pritchard et al. (2010a) utilizaram agitação de $200 \mathrm{rpm}$ por 30 segundos, seguida de $20 \mathrm{rpm}$ por 15 minutos, e obtiveram $83,7 \%$ de remoção de turbidez para água turva preparada com 146 NTU (Nephelometric Turbidity Unit) de turbidez inicial, utilizando $50 \mathrm{mg} / \mathrm{L}$ de sementes de Moringa e 74\% de redução para água turva de rio com turbidez inicial de 45,4 NTU, utilizando $250 \mathrm{mg} / \mathrm{L}$ de sementes de Moringa, demonstrando que mesmo com uma menor turbidez para a segunda água, foi necessário uma maior concentração de semente de Moringa.

Entre os experimentos, para uma mesma condição (comparando na coluna), não houve diferença estatística $(\mathrm{p}>0,05)$, o que indica que indiferente das condições experimentais em termos de agitação e concentração de semente de Moringa oleifera os resultados são iguais, podendo-se conduzir o processo tanto com os parâmetros operacionais de E1 como de E7.

\subsection{Caracterização físico-química do efluente bruto e clarificado}

De acordo com as etapas anteriores, os experimentos E1 e E7 para o efluente sem decantação prévia apresentaram os melhores resultados de clarificação.

Porém, para a etapa de caracterização físico-química do efluente bruto e clarificado optou-se por comparar os valores dos parâmetros dos experimentos E1 e E7 sem decantação prévia e com decantação prévia, pois, mesmo havendo diferença significativa entre as duas condições experimentais, esta diferença se deu em relação à clarificação, sendo que os demais parâmetros não foram avaliados.

Na Tabela 4 estão os resultados da caracterização físico-química do efluente bruto, sem decantação prévia e com decantação prévia para E1 e E7.

Observa-se, que os valores da DQO obtidos para amostras sem decantação prévia foram inferiores aos obtidos para as amostras com decantação prévia. Em relação ao efluente bruto, o processo de clarificação sem decantação prévia 
Tabela 4 - Caracterização físico-química do efluente bruto, clarificado sem decantação prévia e clarificado com decantação prévia (experimentos E1 e E7).

\begin{tabular}{lccccc}
\hline \multirow{2}{*}{ Ensaio } & Efluente & \multicolumn{2}{c}{ Sem decantação } & \multicolumn{2}{c}{ Com decantação } \\
& Bruto & E1 & E7 & E1 & E7 \\
\hline DQO $\left(\mathrm{mgO}_{2} / \mathrm{L}\right)$ & 9.550 & 5.670 & 4.380 & 5.840 & 4.770 \\
Sólidos totais $(\mathrm{g} / \mathrm{L})$ & $21,78 \pm 0,15$ & $6,66 \pm 0,25$ & $8,29 \pm 0,96$ & $3,73 \pm 0,42$ & $3,03 \pm 0,96$ \\
Sólidos dissolvidos $(\mathrm{g} / \mathrm{L})$ & $1,53 \pm 0,44$ & $1,83 \pm 0,23$ & $2,01 \pm 0,17$ & $1,58 \pm 0,07$ & $1,35 \pm 0,46$ \\
Alcalinidade total $\left(\mathrm{mgCaCO}_{3} / \mathrm{L}\right)$ & $331 \pm 1,41$ & $350,5 \pm 2,12$ & $334,5 \pm 0,70$ & $346,5 \pm 0,70$ & $443 \pm 2,82$ \\
Acidez (solução molar \%) & $3,35 \pm 0,13$ & $1,09 \pm 0,06$ & $1,09 \pm 0,06$ & $0,62 \pm 0,06$ & $0,48 \pm 0,00$ \\
$\mathrm{pH}$ & 5,10 & 5,26 & 5,18 & 5,80 & 6,03 \\
\hline
\end{tabular}

Para os experimentos com decantação prévia, as reduções nos valores de DQO foram de 38,85\% para E1 e 50,05\% para E7. Vieira et al. (2012) observaram uma remoção de DQO de $52,2 \%$ para efluente de terminais de distribuição de combustíveis terrestres utilizando a semente de Moringa.

Bhuptawat et al. (2007) ao utilizarem a semente de Moringa para o tratamento de esgoto doméstico obtiveram a DQO inicial do esgoto de $224 \mathrm{mg} / \mathrm{L}$ sendo esta foi reduzida à 196 $\mathrm{mg} / \mathrm{L}$ utilizando uma dosagem de 50 $\mathrm{mg} / \mathrm{L}$, e a DQO de $192 \mathrm{mg} / \mathrm{L}$ foi reduzida à $144 \mathrm{mg} / \mathrm{L}$ utilizando $100 \mathrm{mg} / \mathrm{L}$ de sementes, correspondentes a reduções de $12,5 \%$ e $25 \%$, respectivamente, remoções estas inferiores as obtidas no presente estudo. Bhatia et al. (2006) alcançaram remoção de DQO de $70 \%$ utilizando dosagem aproximada de $1.000 \mathrm{mg} / \mathrm{L}$ de semente de Moringa em efluente de indústria de óleo de palma, sendo esta redução superior a obtida neste estudo, porém utilizando uma concentração aproximadamente 7 vezes maior a otimizada para o efluente da indústria de ingredientes para alimentação animal.

As amostras sem decantação prévia apresentaram redução de sólidos totais de $69,42 \%$ para o experimento E1 e 61,9\% para o experimento E7 em comparação com o efluente bruto. Já amostras com decantação prévia apresentaram redução dos teores de sólidos totais de $82,87 \%$ para E1 e $86,08 \%$ para E7, portanto, os experimentos com decantação prévia apresentaram menores valores de sólidos dissolvidos. Silva et al. (2007) trataram esgoto doméstico com $200 \mathrm{mg} / \mathrm{L}$ de sementes de Moringa e verificaram a redução do nível de sólidos totais de 980 $\mathrm{mg} / \mathrm{L}$ para $782 \mathrm{mg} / \mathrm{L}$ e de sólidos dissolvidos de $969,5 \mathrm{mg} / \mathrm{L}$ para 767,5 $\mathrm{mg} / \mathrm{L}$, correspondendo a reduções de $20,20 \%$ e $20,83 \%$, respectivamente, caracterizando como menores os percentuais de remoção de sólidos quando utilizada maior concentração de semente.

Em relação à alcalinidade, para os experimentos sem decantação prévia verifica-se que houve um leve aumento em relação ao efluente bruto, correspondendo a 5,89\% para E1 e 1,06\% para E7. Para os experimentos com decantação prévia, E1 apresentou acréscimo de 4,68\% na alcalinidade e E7 apresentou acréscimo de 33,8\%. O aumento da alcalinidade pode estar intimamente relacionado com o aumento do $\mathrm{pH}$, diferentemente do encontrado no presente estudo, a alcalinidade inicial de águas residuárias domésticas tratadas com uso de 50 e $100 \mathrm{mg} / \mathrm{L}$ de Moringa por Bhuptawat et al. (2007) se manteve em $215 \mathrm{mg} / \mathrm{L}$ durante os experimentos. Nos estudos de Ndabigengesere et al. (1995) a alcalinidade das águas turvas preparadas também se manteve constante nos experimentos que utilizaram Moringa como coagulante. Cruz et al. (2007) estudaram o efeito da dosagem de Moringa de 0,5, 1 e 2 sementes/L em efluente de viveiro de camarão marinho e observaram que em todos os tratamentos a alcalinidade diminuiu de forma lenta e 
gradual até 10 horas de decantação, e sofreu leve aumento a partir de 12 horas de decantação. Silva et al. (2007) não observaram variação significativa da alcalinidade no tratamento de esgoto doméstico com $200 \mathrm{mg} / \mathrm{L}$ de sementes de Moringa, o valor variou de 311,0 para $306,6 \mathrm{mg} \mathrm{CaCO}_{3} / \mathrm{L}$.

Após a clarificação houve uma redução nos valores de acidez do efluente, sendo os menores valores de acidez correspondentes aos maiores valores de alcalinidade. Os valores de $\mathrm{pH}$ também tiveram um ligeiro aumento após a clarificação, que pode ser em virtude do aumento da alcalinidade e/ou redução da acidez. Ndabigengesere et al. (1995) verificaram em seu estudo que o valor do $\mathrm{pH}$ permaneceu constante em 7,6 para todas as dosagens de semente de Moringa testadas, em comparação com o valor de pH obtido para a água turva tratada com sulfato de alumínio, cujo $\mathrm{pH}$ diminuiu de 7,6 para 4,2 , o que na prática causa a necessidade de mais uma adição química para que este efluente possa seguir para a etapa de biodegradação. $\mathrm{O}$ efluente tratado por Bhuptawat et al. (2007) apresentou $\mathrm{pH}$ inicial 7,22 e a variação observada durante os experimentos foi de 7,15 a 7,29. Bhatia et al. (2006) obtiveram a maior remoção de sólidos suspensos em pH 5 no tratamento de efluente de óleo de palma com sementes de Moringa. No presente estudo o valor de $\mathrm{pH}$ foi apenas determinado e não modificado em virtude de não se alterar as características iniciais do efluente.

Portanto, de acordo com os resultados da caracterização físicoquímica e da clarificação pode-se afirmar que o efluente bruto pode ser tratado diretamente com a adição de semente de Moringa oleifera nas condições testadas, sem haver a necessidade de uma decantação prévia, já que os percentuais de remoção de DQO foram inferiores para o efluente decantado previamente e os valores de $\mathrm{pH}$ permaneceram dentro da faixa aceitável para a etapa de biodegradação.

\section{CONCLUSÕES}

Sementes trituradas de Moringa oleifera apresentam-se como uma alternativa para tratamento de efluente de indústria de ingredientes para alimentação animal. Os valores de percentual de clarificação obtidos foram de 53,20\% para o experimento com 138 $\mathrm{mg} / \mathrm{L}$ de semente de Moringa oleifera, agitação de $100 \mathrm{rpm}$ sendo que o valor de DQO final, obtido após a clarificação teve uma redução de $54,14 \%$.

Comparando-se os experimentos com e sem decantação prévia, verificouse que os valores do percentual de clarificação (\%) foram superiores para os experimentos com adição direta do coagulante no efluente bruto, não havendo, portanto, a necessidade de uma etapa de decantação prévia a etapa de coagulação.

$\mathrm{Na}$ caracterização físico-química, os valores de redução de DQO foram superiores para o efluente bruto adicionado de coagulante em comparação com o efluente decantado previamente.

\section{REFERÊNCIAS}

APHA-American Public Health Association, American Water Works Association, Water Enviromental Federation. Standard Methods for the Examination of Water and Wastewater. Washington, APHA/AWWA/WEF, 1998.

ARVANITOYANNIS, I. S., LADAS, D. 2008. Meat Waste Treatment Methods and Potential Uses. International Journal of Food Science and Technology, 43 (3), 543-559.

BHATIA, S., OTHMAN, Z., AHMAD, A. L. 2010. Pretreatment of Palm Oil Mill Effluent (POME) Using Moringa oleifera Seeds as Natural Coagulant. Journal of Hazardous Materials, 145 (12), 120-126.

BHUPTAWAT, H., FOLKARD, G. K., CHAUDHARI, S. 2007. Innovative Physico-chemical Treatment of Wastewater Incorporating Moringa oleifera Seed Coagulant. Journal of 
Hazardous Materials, 142 (1-2), 477482.

CRUZ, M. W. O., OLIVEIRA, E. G., ARAÚJO FILHO, J. M., HIPÓLITO, M. L. F., LIMA, C. B. 2007. Avaliação da Eficiência de Sementes de Moringa no Tratamento de Efluentes de Viveiros de Camarão Marinho. Revista Ciência Agronômica, 38 (3), 257-263.

FORMENTINI-SCHMITT, D. M., FAGUNDES-KLEN, M.R., VEIT, M.T. BERGAMASCO, R., FERRANDIN, A.T. 2014. Estudo da Eficiência do Composto Ativo de Moringa oleifera Extraída com Soluções Salinas na Tratabilidade de Águas Residuárias da Indústria de Laticínios. Engevista, 16 (2), 221-231.

GALLÃO, M. L., DAMASCENO, L. F., BRITO, E. S. 2006. Avaliação Química e Estrutural da Semente de Moringa. Ciência Agronômica, 37 (1), 106-109.

GHEBREMICHAEL, K. A., GUNARATNA, K.R., HENRIKSSON, H., BRUMER, H., DALHAMMAR, G. 2005. A Simple Purification and Activity Assay of the Coagulant Protein From Moringa oleifera Seed. Water Research, 39 (11), 2338-2344.

KATAYON, S., NOOR, M. M., ASMA, M., GHANI, L. A. A., THAMER, A.A., AZNI, I., AHMAD, J., KHOR, B.C., SULEYMAN, A.M. 2005. Effects of Storage Conditions of Moringa oleifera Seeds on its Performance in Coagulation. Bioresource Technology, 97 (13), 14551460.

LENHARI, J. L. B., HUSSAR, G. J. 2010. Comparação Entre o Uso da Moringa oleifera Lam e de Polímeros Industriais no Tratamento FísicoQuímico do Efluente de Indústria Alimentícia. Revista Engenharia Ambiental, 7 (4), 33-42.

LIMA, R.S., SANTOS, V.B., OLIVEIRA, A. C. P., AZEVEDO, F. M. S. O. Avaliação da Eficiência de
Sementes de Moringa oleifera e de seu Extrato Aquoso como Coagulante Natural para Remoção de Células de Microsystis aeruginosa. II Encontro Nacional de Moringa, 2010. Aracaju, Brasil. 7-3.

MENDES, F. M., COELHO, N.M.M. 2007. Estudo do Uso da Moringa oleifera para Remoção de Prata e Manganês em águas. Horizonte Científico, 1. Disponível em: http://www.seer.ufu.br/index.php/horizon tecientifico/article/viewFile/3787/2792.

MONACO, P. A. V. L, MATOS, A. T., RIBEIRO, I. C. A., NASCIMENTO, F. S., SARMENTO, A. P. 2010. Utilização de Extrato de Sementes de Moringa como Agente Coagulante no Tratamento de Água para Abastecimento e Águas Residuárias. Revista Ambiente e Água, 5 (3), 222-231.

MORAES, L.C.K. 2004. Estudo da Coagulação-Ultrafiltração com o Biopolímero Quitosana para a Produção de Água Potável. Dissertação de Mestrado. Universidade Estadual do Paraná.

NDABIGENGESERE A., NARASIAH, S. K., TALBOT B. G. 1995. Active Agents and Mechanism of Coagulation of Turbid Waters Using Moringa oleifera. Water Research, 29 (2), 703-710.

OKUDA, T., BAES, A. U., NISHIJIMA, W., OKADA, M. 2001. Coagulation Mechanism of Salt Solution - Extracted Active Component in Moringa oleifera Seeds. Water Research, 35 (3), 839-834.

PACHECO, J. W. 2006. Guia técnico ambiental de frigoríficos industrialização de carnes (bovina $e$ suína). São Paulo: CETESB.

PATERNIANI, J. E. S., MANTOVANI, M. C., SANT'ANNA, M. R. 2009. Uso de Sementes de Moringa oleifera para Tratamento de Águas Superficiais. Revista Brasileira de Engenharia Agrícola e Ambiental, 13 (6), 765-771. 
PAULA, S. L., PEREIRA, N. C., COSTA, S. C. Aplicação da Moringa oleifera na Clarificação do Extrato Aquoso de Stevia rebaudiana (bert.) bertoni. I Encontro Nacional de Moringa. 2009. Aracaju, Brasil. 3-8.

PRITCHARD, M., CRAVEN, T., MKANDAWIRE, T., EDMONDSON, A. S., O'NEILL, J. G. 2010a. A Comparison between Moringa oleifera and Chemical Coagulants in the Purification of Drinking Water - An Alternative Sustainable Solution for Developing Countries. Physics and Chemistry of the Earth, 35 (13-14), 798-805.

PRITCHARD, M., CRAVEN, T., MKANDAWIRE, T., EDMONDSON, A. S., O'NEILL, J. G. 2010b. A Study of the Parameters Affecting the Effectiveness of Moringa oleifera in Drinking Water Purification. Physics and Chemistry of the Earth, 35 (13-14), 791797.

SÁNCHEZ-MARTÍN, J., BELTRÁNHEREDIA, J., PERES, J. A. 2012. Improvement of the Flocculation Process in Water Treatment by Using Moringa oleifera Seeds Extract. Brazilian Journal of Chemical Engineering, 29 (3), 495501.

SCHMITT, D. M. F., KLEN, M. R. F., VEIT, M. T., BERGAMASCO, R. Tratamento de águas residuárias da indústria de laticínios pelo processo de coagulação/floculação utilizando a semente de Moringa oleifera. II Encontro Nacional de Moringa. 2010. Aracaju, Brasil. 7-1.

SILVA, F. J. A., MATOS, J. E. X. 2008. Sobre Dispersões de Moringa oleifera para o Tratamento de Água. Revista Tecnologia, 29 (2), 157-163.

SILVA, M. E. R., AQUINO, M. D., SANTOS, A. B. 2007. Pós-Tratamento de Efluentes Provenientes de Reatores Anaeróbios Tratando Esgotos Sanitários por Coagulantes Naturais e Não-naturais.
Revista Tecnológica Fortaleza, 28 (2), 178-190.

SILVA, C. A., SILVEIRA, C. SILVA, F. A., KLEN, M. R. F., BERGAMASCO, R. 2012. Classificação dos Lodos Formados Durante o Processo de Coagulação/Floculação da Água com os Coagulantes Pac e Moringa Oleifera. Engevista, 14 (3), 302-309.

STATSOFT, INC.; Statistica 10.0, St. Tulsa, OK, USA

VIEIRA, R. B., VIEIRA, P. A., CARDOSO, S. L., RIBEIRO, E. J., CARDOSO, E. L. 2012. Sedimentation of Mixed Cultures Using Natural Coagulants for the Treatment of Effluents Generated in Terrestrial Fuel Distribution Terminals. Journal of Hazardous Materials, 231-232, 98-104.

YIN, C. Y. 2010. Emerging Usage of Plant-Based Coagulants for Water and Wastewater Treatment. Process Biochemistry, 45 (9), 1437-1444. 